\title{
Phase 2 Study of Intralesional PV-10 in Refractory Metastatic Melanoma
}

\author{
John F. Thompson, MD ${ }^{1}$, Sanjiv S. Agarwala, MD $^{2}$, B. Mark Smithers, MD $^{3}$, Merrick I. Ross, MD $^{4}$, \\ Charles R. Scoggins, $\mathrm{MD}^{5}$, Brendon J. Coventry, $\mathrm{MD}^{6}$, Susan J. Neuhaus, $\mathrm{MD}^{6}$, David R. Minor, $\mathrm{MD}^{7}$, \\ Jamie M. Singer, $\mathbf{M S}^{\mathbf{8}}$, and Eric A. Wachter, $\mathbf{P h D}^{\mathbf{8}}$
}

${ }^{1}$ Melanoma Institute Australia and the University of Sydney, Sydney, NSW, Australia; ${ }^{2}$ St. Luke's Hospital and Health Network and Temple University, Bethlehem, PA; ${ }^{3}$ Queensland Melanoma Project, Princess Alexandra Hospital, University of Queensland, Woolloongabba, QLD, Australia; ${ }^{4} \mathrm{MD}$ Anderson Cancer Center, Houston, TX; ${ }^{5}$ University of Louisville, Louisville, KY; ${ }^{6}$ University of Adelaide and Royal Adelaide Hospital, Adelaide, SA, Australia; ${ }^{7}$ California Pacific Medical Center, San Francisco, CA; ${ }^{8}$ Provectus Biopharmaceuticals Inc, Knoxville, TN

\begin{abstract}
Purpose. This international, multicenter, single-arm trial assessed efficacy and safety of intralesional rose bengal (PV-10) in 80 patients with refractory cutaneous or subcutaneous metastatic melanoma.

Methods. Sixty-two stage III and 18 stage IV melanoma patients with disease refractory to a median of six prior interventions received intralesional PV-10 into up to 20 cutaneous and subcutaneous lesions up to four times over a 16-week period and were followed for 52 weeks. Objectives were to determine best overall response rate in injected target lesions and uninjected bystander lesions, assess durability of response, and characterize adverse events.

Results. For target lesions, the best overall response rate was $51 \%$, and the complete response rate was $26 \%$. Median time to response was 1.9 months, and median duration of response was 4.0 months, with $8 \%$ of patients having no evidence of disease after 52 weeks. Response was dependent on untreated disease burden, with complete response achieved in $50 \%$ of patients receiving PV-10 to all of their disease. Response of target lesions correlated with bystander lesion regression and the occurrence of locoregional blistering. Adverse events were predominantly mild to moderate and locoregional to the treatment
\end{abstract}

(C) The Author(s) 2014. This article is published with open access at Springerlink.com

First Received: 23 June 2014;

Published Online: 28 October 2014

E. A. Wachter, $\mathrm{PhD}$

e-mail: wachter@pvct.com site, with no treatment-associated grade 4 or 5 adverse events.

Conclusions. Intralesional PV-10 yielded durable local control with high rates of complete response. Toxicity was confined predominantly to the injection site. Cutaneous bystander tumor regression is consistent with an immunologic response secondary to ablation. This intralesional approach for local disease control could be complementary to current and investigational treatments for melanoma.

Patients with regional metastatic melanoma (i.e., local, in-transit, and satellite recurrence) have a long median survival, but their clinical management can be challenging due to disease heterogeneity and frequent and persistent proliferation of lesions. ${ }^{1-5}$ Refractory lesions are often highly unpleasant for the patient; can lead to ulceration, bleeding, or infection; and can affect extensive areas for prolonged intervals before distant metastasis. ${ }^{6}$ Some patients with established visceral metastases also have dermal disease and similarly troublesome symptoms. Current treatment guidelines include surgical excision, local ablation, intralesional therapy, and regional chemotherapy, along with targeted drugs (e.g., against the V600E $B R A F$ mutation). ${ }^{7}$ There are currently few drug therapies, especially for $B R A F$ wild-type patients, that can provide rapid, sustained reduction of tumor burden with low toxicity.

Rose bengal disodium (RB) has been used as an intravenous liver function diagnostic and is still used as a topical ophthalmic diagnostic. ${ }^{89}$ PV-10 (a sterile, nonpyrogenic $10 \%$ solution of RB in $0.9 \%$ saline) is a small 
(a)
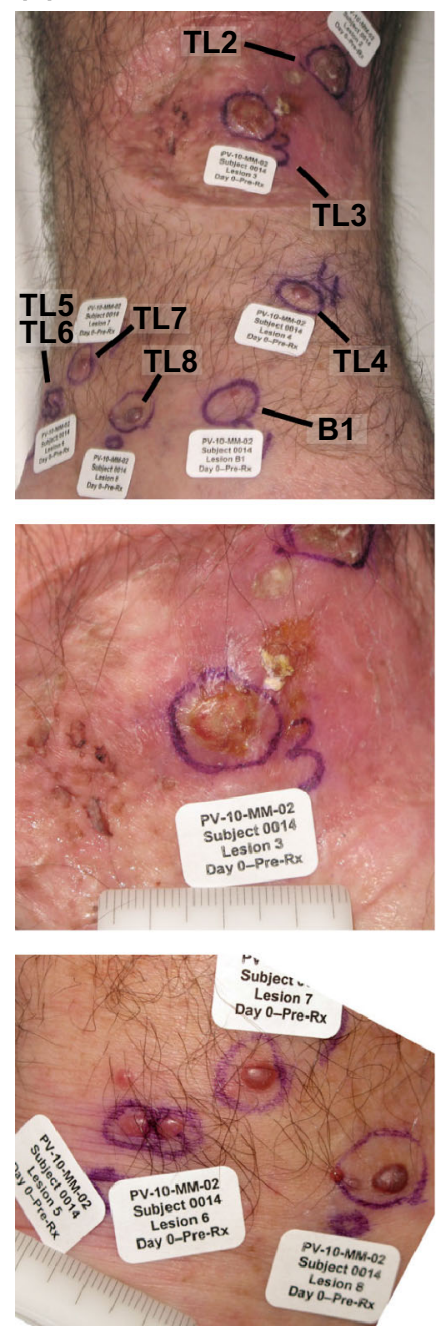

Pre-Treatment

(b)

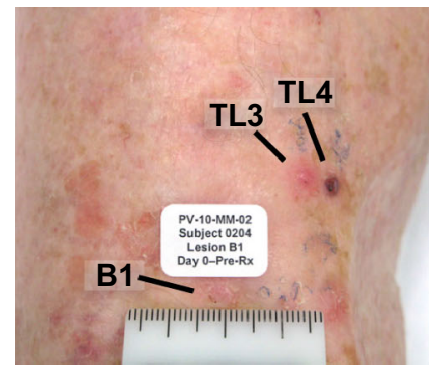

Pre-Treatment
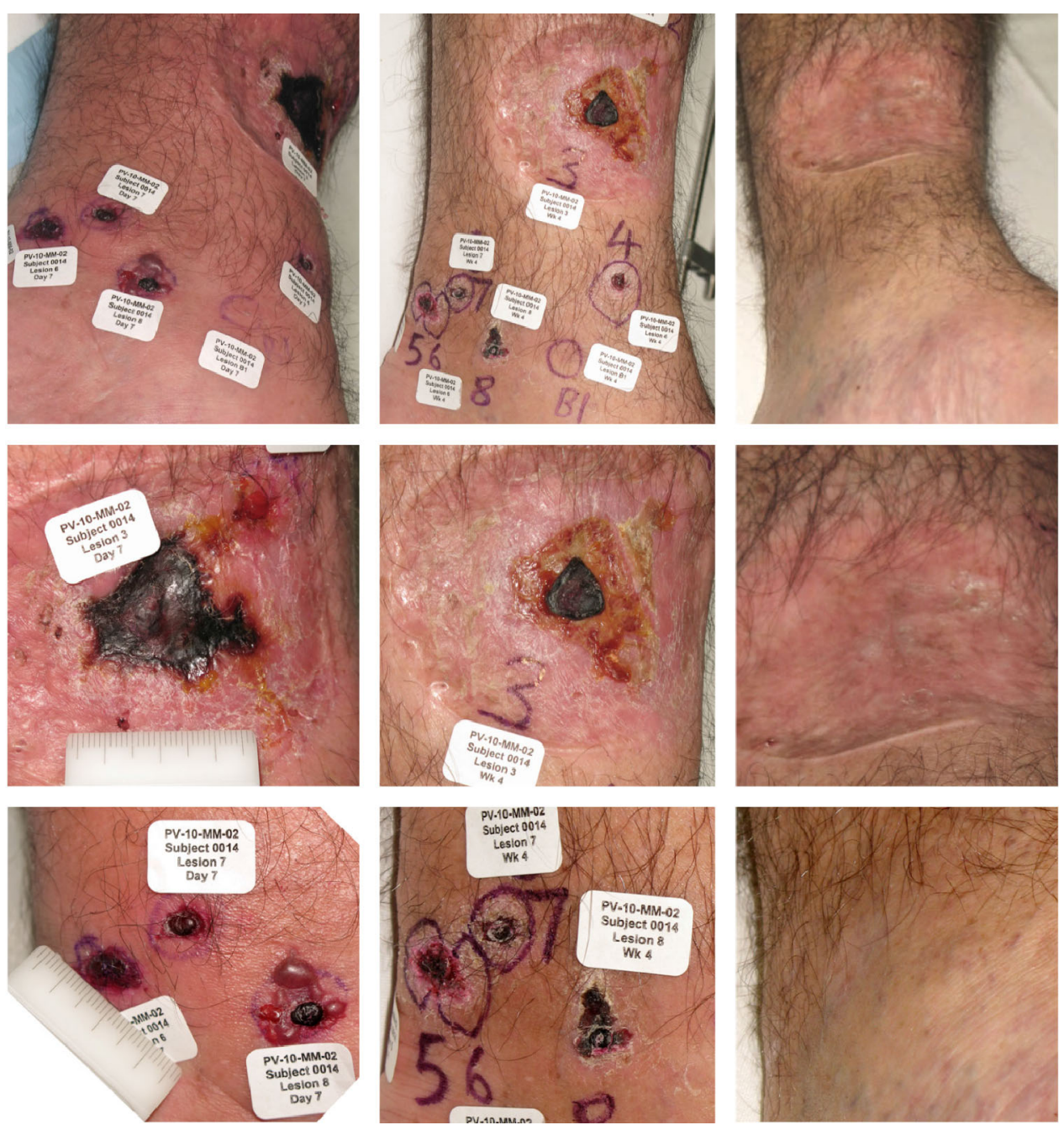

Day 7

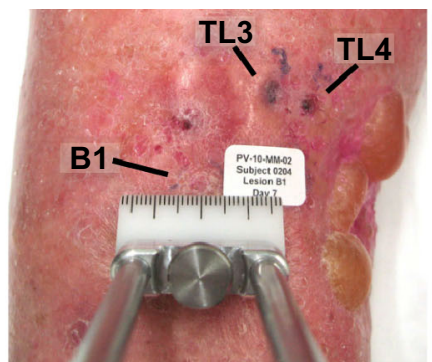

Day 7

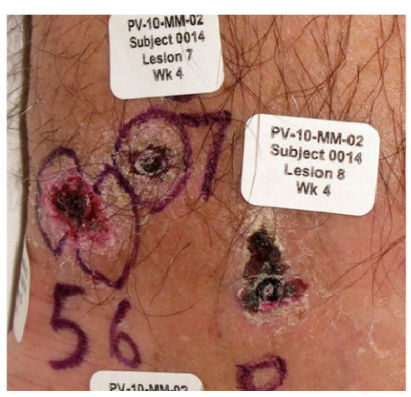

Week 4

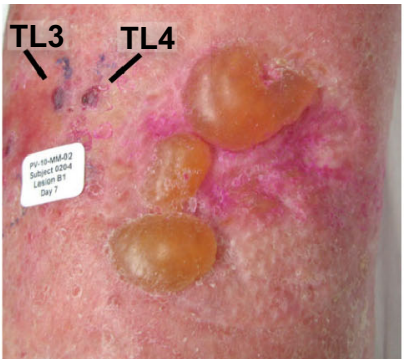

Day 7 (Alt View)

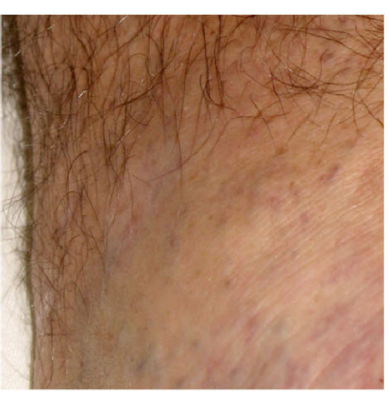

Week 24

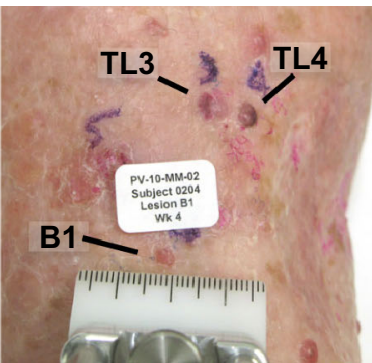

Week 4 molecule agent for intralesional (IL) injection into tumors. After IL injection, PV-10 accumulates in tumor lysosomes resulting in rapid lysis of tumor cells. ${ }^{10}$ This primary ablative effect may induce a secondary tumor-specific $\mathrm{T}$ cell-mediated antitumor immune response. ${ }^{11,12}$ In a phase 1 study, a single IL dose of PV-10 was well tolerated, with a best overall response rate (BORR) at 12 weeks of $55 \%$. Notably, 3 of 11 patients had no evidence of recurrence for at least 28 months. ${ }^{13}$ Subsequently, this phase 2 study was undertaken, allowing repeat dosing of PV-10 and following patients for up to 52 weeks (clinical trial NCT00521053). 
4 FIG. 1 Example ablative effects of intralesional PV-10 in treatmentrefractory melanoma. a Regional and close-up views of patient 0014 , male, age 48, with stage IIIB melanoma of the lower extremity recurrent after 3 previous surgical interventions, treated once with $1.3 \mathrm{~mL} \mathrm{PV-10}$ into 10 target lesions on day 0 (bystander lesion B1 uninjected). All lesions were undetectable by ultrasound at week 24 . Possible recurrence of target lesions TL2, TL3, TL4, TL8, TL9, and TL10 detected by ultrasound at week 36 (each 1-3 mm maximum diameter; none sampled) with TL9 and TL10 remaining at week 52 (2-3 mm) without further treatment. Extensive eschar of TL2 and TL3 within surgical scar is evident at day 7 with marked improvement by week 4. Small (grade 1) treatment-emergent perilesional blisters are evident in close-up view of TL8 at day 7. b Example of treatment-emergent blisters occurring in $40 \%$ of the patient population and correlated with increased response rate of target lesions. Generally presenting as tense bullae 1-7 days after treatment, blisters typically resolved within 4 weeks with or without medication intervention. Close-up views of patient 0204, female, age 82 years, with stage IIIB melanoma of the lower extremity recurrent after four previous surgical interventions, treated once with $0.8 \mathrm{~mL}$ PV-10 into 8 target lesions on day 0 (bystander lesion B1 uninjected). Grade 2 blistering developed in a surgical scar medial to target lesions TL3 and TL4 within 4 days, with full resolution within 1 week without intervention

\section{PATIENTS AND METHODS}

\section{Study Design}

Eighty patients were enrolled onto this international, multicenter, open-label, single-agent study. The governing institutional ethics committee for each study center approved the study protocol, and all patients provided written informed consent. Eligible patients had biopsyproven confirmation of melanoma and at least one cutaneous or subcutaneous lesion $\geq 0.2 \mathrm{~cm}$ in diameter that could accurately be measured by ruler/caliper or ultrasound. They received a single IL injection of PV-10 to uniformly infiltrate each of up to 20 study lesions on day 0 (i.e., $\leq 10$ target and $\leq 10$ nontarget dermal lesions) using $0.5 \mathrm{~mL} \mathrm{PV}-10$ per $\mathrm{cm}^{3}$ of lesion volume. Treatment could be repeated at weeks 8, 12, and 16 for new nontarget lesions or existing target or nontarget lesions not exhibiting complete response. PV-10 was not injected into nodal or visceral lesions. One or two additional measureable, biopsy-confirmed dermal lesions could be designated for assessment of bystander response and were followed but not injected. Body mapping and digital photography with lesion identification markers and reference scale were used to accurately track all study lesions. Patients were followed for 52 weeks after initial PV-10 treatment (i.e., for at least 36 weeks after their last possible PV-10 treatment).

Study evaluations, including lesion photography, were performed at screening, on the day of PV-10 administration, at 1 day and 7 days after injection, and every 4 weeks thereafter during the treatment portion of the study (i.e., through week 16), and during long-term follow-up at weeks 24, 36, and 52. Radiologic assessments of visceral disease status were performed every 12 weeks throughout the study, and patients were transitioned into survival follow-up if at any time the investigator identified clinical or radiologic evidence of distant progression. No other melanoma therapy was permitted during the study interval. Treatment for concurrent or intercurrent illness, and wound care or management of pain, were allowed at each investigator's discretion. Adverse events (AEs) were monitored over the study interval.

The study utilized a modified Fleming two-stage design. ${ }^{14}$ Interim assessment upon accrual of the first 40 patients required an objective response in at least eight patients to substantiate a true response rate between 10 and $30 \%$. Full accrual allowed testing of a projected $30 \%$ primary efficacy rate (95\% confidence interval 20-40). Post hoc exploratory analyses were undertaken to understand results in certain subgroups.

\section{Criteria for Analyses}

The primary end point of the study was BORR of target lesions, with secondary end points of progressionfree survival (PFS) and duration of response, overall survival (OS), by-lesion BORR, and bystander lesion BORR, along with assessment of AEs, quality-of-life (assessed using the EORTC QLQ-C30 instrument), lesion pain (assessed via a $100 \mathrm{~mm}$ visual analog scale), and pharmacokinetics. $^{15-17}$

Response Evaluation Criteria in Solid Tumors (RECIST) was modified (mRECIST) to allow: (1) designation of cutaneous or subcutaneous lesions $\geq 0.2 \mathrm{~cm}$ in diameter as target lesions; (2) up to 10 cutaneous and subcutaneous target lesions to be followed; and (3) assessment of disease progression against baseline sum of longest diameters of target lesions, thereby allowing clinically insignificant progression (including locoregional appearance of new cutaneous or subcutaneous nontarget lesions) to be treated to week $16 .^{18}$ Standard thresholds for percentage change in sum of longest diameters were used to define complete response (CR), partial response (PR), stable disease (SD), and progressive disease (PD). All lesions specified at baseline were followed over the course of the study with last observations carried forward for any lesions not measurable at a visit; response assessment was censored for missed visits. When eschar was reported, a standard query was used to ascertain lesion status. An example of measurable eschar that eclipsed baseline measurement is illustrated in Fig. 1a. To mitigate such artifacts and allow detection of regrowth after initial ablation, the first formal response assessment occurred at 
week 8 and was repeated at each visit thereafter. Patients failing to reach assessment at week 8 were deemed not evaluable and classified as PD.

\section{RESULTS}

\section{Patients}

Eighty patients (intent-to-treat population, ITT; median age 70 years, range 33-97 years; Table 1) were enrolled over 19 months at 7 study centers: 3 in Australia and 4 in the United States. All patients had recurrent, locally advanced melanoma after a median of 6 previous interventions (range 1-19), and most had received multiple classes of treatment. The median time from initial melanoma diagnosis to initial PV-10 treatment was 42.3 months (range 1.7-752). Study lesions comprised a substantial total tumor burden with a median sum of longest diameters of $6.3 \mathrm{~cm}$ (range $0.9-21.0 \mathrm{~cm}$ ), with a median of 7.5 study lesions per patient (range 1-22). The most prevalent comorbidity was hypertension (51\% of patients), followed by hypercholesterolemia (23\%) and depression (19\%).

Patients received a mean of 1.8 PV-10 treatment cycles (median 2); 35 patients received a single cycle, and three patients received the maximum four cycles allowed by protocol.

\section{Efficacy}

Half of the ITT patients achieved an objective response in their target lesions (51\% BORR, $26 \% \mathrm{CR}+25 \% \mathrm{PR}$ ) (Table 2), with $8 \%$ of patients having no evidence of disease after 52 weeks. Locoregional disease control (SD or better) was achieved in $69 \%$ of patients, while $16 \%$ were not evaluable as a result of progression before week 8 . (This occurred predominantly in patients with extensive disease burden not injected with PV-10.) Onset of response occurred at a median of 1.9 months, corresponding with the first assessment of response. The median duration of response was 4.0 months (by RECIST) but was not met in the study interval when assessed by mRECIST. Time-to-event data for objective response are represented in Fig. 2, and PFS data for all patients are summarized in Table 2 .

Response rates by lesion among 491 target lesions in the ITT population were similar to those by patient, with $53 \%$ of lesions achieving CR, $5 \% \mathrm{PR}$, and $12 \% \mathrm{SD}$.

Among the 42 patients with designated bystander lesions, $26 \%$ experienced CR of their uninjected bystander lesions, $7 \%$ PR, and $17 \%$ SD. Response in bystander lesions strongly correlated with that of patients' target lesions: CR or PR in target disease was associated with $56 \% \mathrm{CR}$ and $6 \% \mathrm{PR}$ in bystander lesions; in contrast, patients who did not experience
TABLE 1 Patient characteristics

\begin{tabular}{|c|c|c|}
\hline Characteristic & $N$ & $\%$ \\
\hline \multicolumn{3}{|l|}{ Gender } \\
\hline Male & 48 & 60 \\
\hline Female & 32 & 40 \\
\hline \multicolumn{3}{|l|}{ Age } \\
\hline$<70 \mathrm{y}$ & 39 & 49 \\
\hline$\geq 70 \mathrm{y}$ & 41 & 51 \\
\hline \multicolumn{3}{|l|}{ Disease stage } \\
\hline III & 62 & 78 \\
\hline IIIB & 38 & 48 \\
\hline IIIC & 24 & 30 \\
\hline IV & 18 & 23 \\
\hline IV M1a & 3 & 4 \\
\hline IV M1b & 5 & 6 \\
\hline IV M1c & 10 & 13 \\
\hline \multicolumn{3}{|l|}{ Treatment history } \\
\hline \multicolumn{3}{|l|}{ Prior therapy } \\
\hline Surgical excision & 80 & 100 \\
\hline Nodal biopsy & 50 & 63 \\
\hline Regional chemotherapy & 19 & 24 \\
\hline Immunotherapy & 17 & 21 \\
\hline Radiotherapy & 17 & 21 \\
\hline Investigational agents & 11 & 14 \\
\hline Systemic chemotherapy & 10 & 13 \\
\hline Distal amputation & 7 & 9 \\
\hline Other & 6 & 8 \\
\hline No prior systemic therapy & 45 & 56 \\
\hline Prior systemic therapy & 35 & 44 \\
\hline \multicolumn{3}{|l|}{ Tumor burden in skin } \\
\hline$<10$ lesions & 44 & 55 \\
\hline$\geq 10$ lesions & 29 & 36 \\
\hline Too numerous to count & 7 & 9 \\
\hline \multicolumn{3}{|l|}{ ECOG status } \\
\hline 0 & 53 & 66 \\
\hline 1 & 25 & 31 \\
\hline 2 & 2 & 3 \\
\hline
\end{tabular}

ECOG Eastern Cooperative Oncology Group

an objective response of their target lesions had $6 \% \mathrm{CR}$ and $12 \%$ PR of their bystander lesions $\left(P=0.023\right.$, BORR by $\chi^{2}$ test).

Median OS was not reached for the ITT population. Mean OS for stage III patients was $>12$ months (89\% 1-year survival, median not reached), while for stage IV patients, median survival was 6.5 months (39\% 1-year survival).

Because the protocol limited PV-10 treatment to the first 16 weeks, 11 patients subsequently withdrew to receive further PV-10 treatment under alternative protocols. 
TABLE 2 Objective response of target lesions

\begin{tabular}{|c|c|c|c|c|c|c|c|c|c|c|}
\hline \multirow{3}{*}{$\begin{array}{l}\text { Response of target lesion } \\
\text { No. of patients }\end{array}$} & & & \multicolumn{8}{|c|}{ Patients categorized by disease burden at baseline } \\
\hline & \multicolumn{2}{|c|}{$\begin{array}{l}\text { ITT } \\
\text { population }\end{array}$} & \multicolumn{2}{|c|}{$\begin{array}{l}\text { All lesions } \\
\text { treated }\end{array}$} & \multicolumn{2}{|c|}{$\begin{array}{l}\text { Bystanders } \\
\text { untreated }\end{array}$} & \multicolumn{2}{|c|}{$\begin{array}{l}10 \text { or fewer untreated skin } \\
\text { lesions }\end{array}$} & \multicolumn{2}{|c|}{$\begin{array}{l}\text { TNTC or stage } \\
\text { IV }\end{array}$} \\
\hline & 80 & $\%$ & 28 & $\%$ & 26 & $\%$ & 7 & $\%$ & 19 & $\%$ \\
\hline $\mathrm{CR}$ & 21 & 26 & 14 & 50 & 6 & 23 & 1 & 14 & 0 & 0 \\
\hline PR & 20 & 25 & 6 & 21 & 8 & 31 & 1 & 14 & 5 & 26 \\
\hline SD & 14 & 18 & 3 & 11 & 8 & 31 & 1 & 14 & 2 & 11 \\
\hline $\mathrm{PD}(\mathrm{PD}+\mathrm{NEV})^{\mathrm{b}}$ & 25 & 31 & 5 & 18 & 4 & 15 & 4 & 57 & 12 & 63 \\
\hline NEV: progression before week $8^{\mathrm{b}}$ & 13 & 16 & 2 & 7 & 1 & 4 & 3 & 43 & 7 & 37 \\
\hline $\mathrm{CR}+\mathrm{PR}$ & 41 & 51 & 20 & $71^{\mathrm{c}}$ & 14 & 54 & 2 & 29 & 5 & 26 \\
\hline $\mathrm{CR}+\mathrm{PR}+\mathrm{SD}$ (locoregional disease control) & 55 & 69 & 23 & 82 & 22 & 85 & 3 & 43 & 7 & 37 \\
\hline Mean PFS, mo ${ }^{\mathrm{d}}$ & 8.2 & & $9.8^{\mathrm{e}}$ & & $8.9^{\mathrm{f}}$ & & 6.0 & & 2.6 & \\
\hline
\end{tabular}

ITT intent to treat, $T N T C$ too numerous to count, $C R$ complete response, $P R$ partial response, $S D$ stable disease, $P D$ progressive disease, $N E V$ not evaluable, $P F S$ progression-free survival

${ }^{a}$ Median number of untreated lesions: 5

${ }^{\mathrm{b}}$ Patients who were not evaluable were tracked separately but combined with PD for tabulation of outcome

${ }^{c} P=0.006$ vs. TNTC or stage IV subgroup, BORR by $\chi^{2}$ test

${ }^{\mathrm{d}}$ PFS by mRECIST, maximum follow-up duration 12 months

e $P<0.01$ vs. TNTC or stage IV subgroup, by log-rank test

${ }^{\mathrm{f}} P=0.04$ vs. TNTC or stage IV subgroup, by log-rank test

\section{Safety}

All patients experienced one or more $\mathrm{AE}$ during the study (Table 3); most were grade 1 or grade 2, while $15 \%$ of patients had at least one grade $3 \mathrm{AE}$ deemed at least possibly related to study treatment. The most common AEs occurred at the injection site, led by transient pain (reported by $80 \%$ of patients), edema (41\%), and vesicles (39\%). Six patients experienced mild $(4 \%)$ or moderate $(4 \%)$ injection site photosensitivity, and one (1\%) experienced a severe generalized photosensitivity reaction. All of these resolved without sequelae. No life-threatening or fatal AEs at least possibly related to the study treatment were reported.

Quality-of-life assessment throughout the study interval showed no substantial change from baseline on any quality-of-life dimension after PV-10 treatment. Pain scores indicated transient pain in treated lesions during the first week after treatment that generally resolved to baseline within 4 weeks. Approximately $60 \%$ of patients received local anesthesia at the time of PV-10 injection.

\section{Pharmacokinetics}

Pharmacokinetic data were consistent with the literature on RB and illustrate PV-10 clearance via an apparent biexponential process, with a rapid initial distribution/absorption phase occurring during the first $24 \mathrm{~h} \quad\left(\mathrm{k}_{\mathrm{D} / \mathrm{A}}=0.0020 \mathrm{~min}^{-1}\right.$, $\mathrm{t}_{1 / 2, \mathrm{D} / \mathrm{A}}=5.9 \mathrm{~h}$ ), followed by slower terminal elimination $\left(\mathrm{k}_{\mathrm{E}}=0.00012 \mathrm{~min}^{-1}, \mathrm{t}_{1 / 2, \mathrm{E}}=100 \mathrm{~h}\right) .{ }^{19}$ Relatively low uptake during the initial phase (geometric mean $\% \mathrm{AUC} \infty=17.3 \%$ ) and intercepts for the initial and terminal phases (427 and $73 \mathrm{ng} /$ $\mathrm{mL}$, respectively) are consistent with prolonged retention of drug in injected lesions, with potentially significant systemic exposure only during the initial phase.

\section{Untreated Disease Burden}

Although only cutaneous and subcutaneous lesions were injected, the study enrolled patients with stable visceral disease (including brain, lung, and liver metastases) who also had injectable dermal disease. To test for a relationship of response to untreated disease burden, patients were classified according to their reported tumor burden at baseline: all known disease treated with PV-10 (28 patients); all known disease treated with PV-10 (with the exception of 12 uninjected bystander lesions) (26 patients); 10 or fewer untreated and unmeasured dermal lesions (7 patients); and dermal disease burden classified as too numerous to count or as stage IV disease (19 patients). For the 54 patients in the first two subgroups, their study lesions, including bystander lesions, represented all documented disease at baseline. These patients, who received PV-10 to all or substantially all of their disease burden, achieved markedly higher response rates compared to patients with substantial untreated disease burden (Table 2). 


\section{Locoregional Blistering}

Another exploratory analysis was undertaken to understand the relevance of locoregional vesicles (blistering). Transient, fluid-filled bullae were observed in $40 \%$ of patients (23\% grade $1,16 \%$ grade 2 , and $1 \%$ grade 3 , including one occurrence reported as possible grade 1 photosensitivity), both perilesional and locoregional and treatment emergent within 1-7 days of PV-10 administration. Onset was independent of dose with no apparent relationship to prior PV-10 administration (Fig. 1). These generally resolved within 4 weeks, with or without medication intervention and without long-term sequelae; blistering was associated with a marked increase in response: $44 \%$ of patients with blisters experienced CR, versus $15 \%$ without blisters $(P=0.008)$.

\section{Age, Sex, Treatment History, and Investigator}

Exploratory analyses were undertaken to assess relevance of demographics, treatment history, and investigator. Equivalent target lesion responses occurred in patients above and below the median age (54 vs. $49 \%$ BORR, $P=0.8)$ and for men and women (58 vs. $41 \%, P=0.2$ ). Dichotomization according to treatment history (systemic or regional chemotherapy or immunotherapy vs. naive patients) showed no significant difference in target lesion response ( 43 vs. $58 \%, P=0.3$ ). Similar response rates were observed across study centers, with all centers reporting at least one patient experiencing PR or better (Fig. 2), and with five of the seven centers reporting patients with no evidence of disease after 12 months. Patterns of AEs were also similar across centers.

\section{Visceral Disease}

Although the study was not designed to quantitatively follow lesions in visceral organs, comprehensive radiologic imaging provided some insight into whether PV-10 could have an impact on visceral disease. While a substantial fraction patients with stage IV disease were classified as not evaluable due to early progression (Table 2), four patients experienced SD or PR of their visceral disease (including patients with multiple pleural and hepatic metastases); three of these patients also exhibited SD or better outcome in their target lesions, similar to the correlation of bystander response to that of target lesions. Seven stage IV patients survived through the end of the 52-week follow-up interval, including 4 of 10 patients with M1c disease.
FIG. 2 Temporal response of all responding patients (i.e., CR or PR in up to 10 cutaneous and subcutaneous target lesions). The 21 patients who experienced CR are shown in blue; the 16 stage III patients experiencing PR are shown in white; and the 4 stage IV patients experiencing PR are shown in yellow. Black bands indicate time of initial response. Patients who withdrew early to receive further PV-10 treatment under alternative protocols are designated with a diamond; patients with ongoing response at end of study interval are designated with an arrow; those with no evidence of disease at the end of the study interval are designated with a plus sign

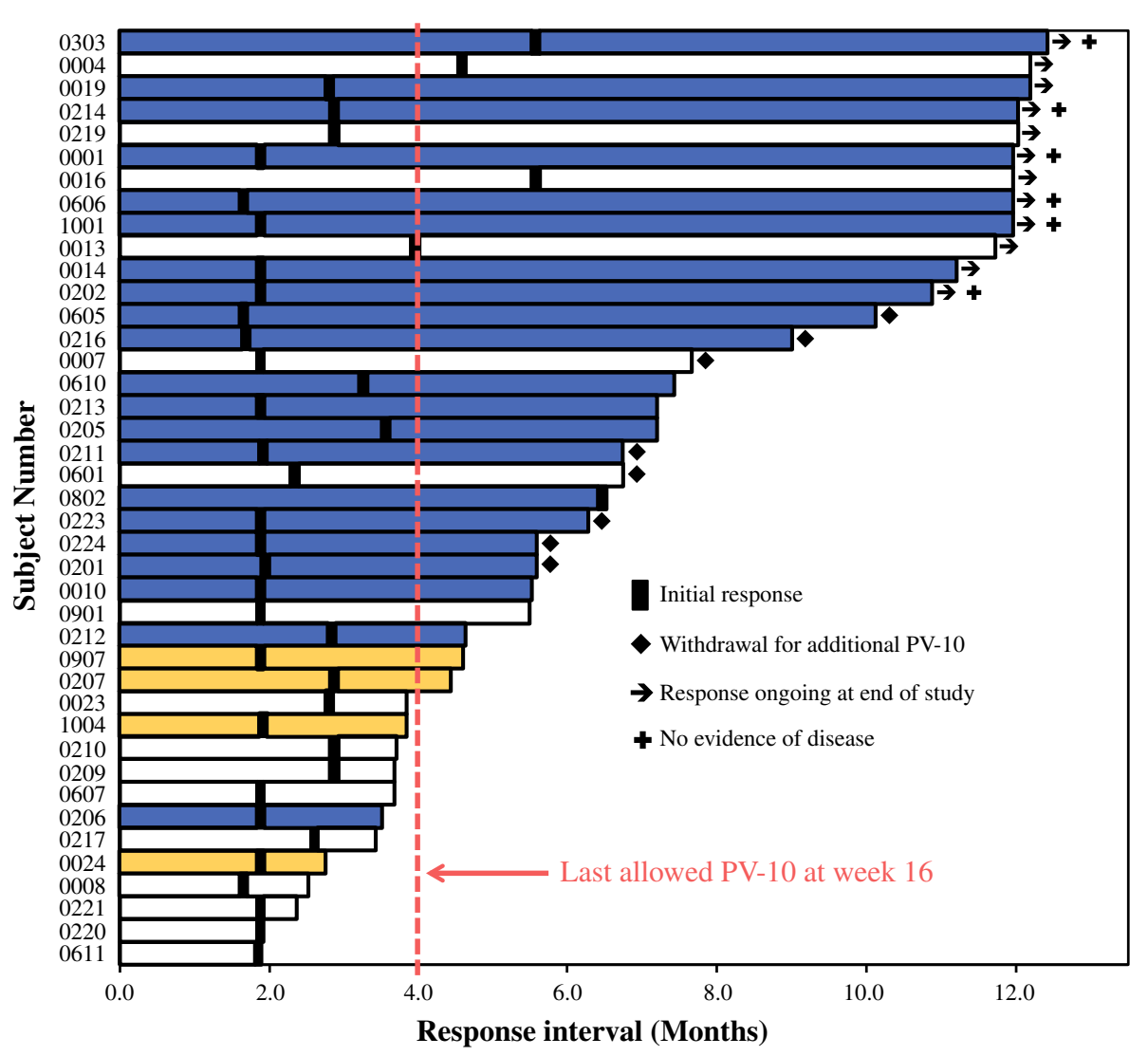


TABLE 3 Most frequent adverse events at least possibly related to study treatment

\begin{tabular}{|c|c|c|}
\hline System organ class and preferred term ${ }^{\mathrm{a}}$ & $\begin{array}{l}\text { Adverse ev } \\
\text { population, }\end{array}$ & $\begin{array}{l}\mathrm{ts}^{\mathrm{b}}(\mathrm{ITT} \\
=80)\end{array}$ \\
\hline & $\begin{array}{l}\text { CTCAE } \\
\text { grade }\end{array}$ & Total \\
\hline & $\begin{array}{lll}1 & 2 & 3\end{array}$ & \\
\hline
\end{tabular}

General disorders and administration site conditions

\begin{tabular}{|c|c|c|c|c|c|}
\hline Injection site pain & 29 & 25 & 10 & 64 & 80 \\
\hline Injection site edema & 19 & 14 & 0 & 33 & 41 \\
\hline Injection site vesicles & 17 & 13 & 1 & 31 & 39 \\
\hline Injection site discoloration $^{c}$ & 13 & 12 & 0 & 25 & 31 \\
\hline Injection site swelling & 14 & 7 & 1 & 22 & 28 \\
\hline Injection site pruritus & 14 & 3 & 0 & 17 & 21 \\
\hline Injection site erythema & 6 & 4 & 1 & 11 & 14 \\
\hline Injection site infection & 3 & 2 & 1 & 6 & 8 \\
\hline Injection site inflammation & 0 & 6 & 0 & 6 & 8 \\
\hline Injection site photosensitivity reaction ${ }^{\mathrm{d}}$ & 3 & 3 & 0 & 6 & 8 \\
\hline Injection site ulcer & 4 & 1 & 0 & 5 & 6 \\
\hline Peripheral edema & 3 & 0 & 1 & 4 & 5 \\
\hline Fatigue & 3 & 1 & 0 & 4 & 5 \\
\hline Injection site rash & 4 & 0 & 0 & 4 & 5 \\
\hline Injection site warmth & 2 & 2 & 0 & 4 & 5 \\
\hline Lethargy & 3 & 1 & 0 & 4 & 5 \\
\hline Injection site cellulitis & 0 & 2 & 1 & 3 & 4 \\
\hline \multicolumn{6}{|l|}{ Gastrointestinal disorders } \\
\hline Diarrhea & 5 & 0 & 0 & 5 & 6 \\
\hline Nausea & 2 & 3 & 0 & 5 & 6 \\
\hline Dysphagia & 0 & 0 & 1 & 1 & 1 \\
\hline \multicolumn{6}{|l|}{ Nervous system disorders } \\
\hline Headache & 11 & 2 & 0 & 13 & 16 \\
\hline \multicolumn{6}{|l|}{ Skin and subcutaneous tissue disorders } \\
\hline Photosensitivity reaction $^{\mathrm{d}}$ & 0 & 0 & 1 & 1 & 1 \\
\hline
\end{tabular}

ITT intent to treat, CTCAE Common Terminology Criteria for Adverse Events

a System organ class and preferred term are based on the MedDRA version 13.0 terminology dictionary. Locoregional adverse events were coded to "injection site" preferred terms to differentiate these from systemic events

${ }^{b}$ Includes all AEs with an incidence of $5 \%$ or higher and all CTCAE grade 3 and higher AEs; there were no treatment-related grade 4 or 5 AEs reported. If a patient experienced an AE more than once during the study, the greatest severity is presented

${ }^{c}$ Discoloration locoregional to injected lesions

${ }^{\mathrm{d}}$ Combined incidence of injection site and skin and subcutaneous tissue photosensitivity reactions: $9 \%$

\section{DISCUSSION}

Patients enrolled onto this study had treatment-refractory cutaneous and subcutaneous metastatic melanoma accessible to injection and were not candidates for systemic therapy as a result of age, comorbidity, refractory disease, or drug unavailability; one quarter had visceral metastases plus injectable disease of the skin.

The primary ablative effect of PV-10 is evident upon minimal intervention (Fig. 1a) and illustrates potentially rapid durable disease control (Fig. 2). The predominantly locoregional AE profile contrasts with global morbidities reported for many systemic and emerging local therapies. ${ }^{20-28}$ Response typically occurred after one or two PV10 treatment cycles versus six or more cycles for other recent investigational IL therapies, with response observed in treated and untreated disease. ${ }^{29-32}$

Untreated tumor burden had a major impact on response: patients receiving injections to most or all tumor deposits exhibited high rates of durable response, a trend that may signify abrogation of immunosubversion by untreated tumor burden. ${ }^{33-35}$ Simultaneous reduction of tumor burden and immune stimulation with PV-10 has proven powerful in animal models of metastasis, and correlation of response in injected and uninjected disease in this and previous clinical studies is consistent with such results. ${ }^{11,13}$ Emerging evidence of a functional immune response secondary to ablation (including increased levels of cytotoxic $\mathrm{CD}^{+}$and $\mathrm{CD} 8^{+} \mathrm{T}$ cells in peripheral blood of patients refractory to immune checkpoint inhibitors and targeted therapies) bolsters the potential relevance of the observed bystander effect. ${ }^{12}$ Association of improved outcome with locoregional blistering suggests that this $\mathrm{AE}$ deserves further investigation.

Three patients from this study experienced unexpectedly positive responses upon subsequent radiotherapy of previously injected, uninjected, and new lesions. ${ }^{36}$ This suggests that the combination of PV-10 with other treatments may have merit in advanced-stage disease with substantial tumor burden inaccessible to injection. In particular, the tumor-specific immune stimulation resulting from PV-10 ablation is potentially additive or synergistic with nonspecific immunotherapies. ${ }^{12,37}$

In summary, intralesional PV-10 elicited robust and durable tumor regression in refractory cutaneous and subcutaneous melanoma with transient locoregional toxicity. The primary ablative effect of PV-10 reduced the size of injected tumors quickly, while regression of uninjected bystander lesions is consistent with a secondary immune response. These data suggest that PV-10 has utility in the management of melanoma patients with injectable cutaneous and subcutaneous disease. Future studies will comprehensively assess the effect of PV-10 on PFS to document potential longer-term benefits of locoregional disease control.

ACKNOWLEDGMENT Thompson, Agarwala, Smithers, Ross, Scoggins, Coventry, Neuhaus, and Minor have received research funding from Provectus Biopharmaceuticals. Singer and Wachter are employees of Provectus Biopharmaceuticals and have stock ownership in Provectus Biopharmaceuticals. 
OPEN ACCESS This article is distributed under the terms of the Creative Commons Attribution License which permits any use, distribution, and reproduction in any medium, provided the original author(s) and the source are credited.

\section{REFERENCES}

1. Balch CM, Gershenwald JE, Soong SJ, Thompson JF, Atkins MB, Byrd DR, et al. Final version of 2009 AJCC melanoma staging and classification. J Clin Oncol. 2009;27:6199-206.

2. Gimbel MI, Delman KA, Zager JS. Therapy for unresectable, recurrent and in transit extremity melanoma. Cancer Control. 2008; 15:225-32.

3. Testori A, Faries MB, Thompson JF, Pennacchioli E, Deroose JP, van Geel AN, et al. Local and intralesional therapy of in-transit melanoma metastases. J Surg Oncol. 2011;104:391-6.

4. Speicher PJ, Tyler DS, Mosca PJ. Management of in-transit malignant melanoma. In: Duc GHT, editor. Melanoma-from early detection to treatment. http://www.intechopen.com/books/ melanoma-from-early-detection-to-treatment/management-of-intransit-malignant-melanoma.

5. Ross MI. Intralesional therapy with PV-10 (rose bengal) for intransit melanoma. J Surg Oncol. 2014;109:314-9.

6. Temple-Oberle CF, Byers BA, Hurdle V, Fyfe A, McKinnon JG. Intra-lesional interleukin-2 therapy for in transit melanoma. $J$ Surg Oncol. 2014;109:327-31.

7. National Comprehensive Cancer Network. NCCN clinical practice guidelines in oncology, melanoma, version 4.2014. http:// www.ncen.org/.

8. Delprat GD, Epstein NN, Kerr WJ. A new liver function test. The elimination of rose bengal when injected into the circulation of human subjects. Arch Intern Med. 1924;34:533-41.

9. Marsh RJ, Fraunfelder FT, McGill JI. Herpetic corneal epithelial disease. Arch Ophthalmol. 1976;94:1899-902.

10. Wachter E, Dees C, Harkins J, Fisher W, Scott T. Imaging photosensitizer distribution and pharmacology using multiphoton microscopy. In: Farkas DL, Leif RC, editors. Proceedings of SPIE, Optical diagnostics of living cells V (Vol. 4622). Bellingham. 2002. p. 112-8.

11. Toomey P, Kodumudi K, Weber A, Kuhn L, Moore E, Sarnaik AA, et al. Intralesional injection of rose bengal induces a systemic tumor-specific immune response in murine models of melanoma and breast cancer. PLoS One. 2013;8:e68561.

12. Sarnaik A, Crago G, Liu H, Kodumudi K, Weber A, McCardle T, et al. Assessment of immune and clinical efficacy after intralesional PV-10 in injected and uninjected metastatic melanoma lesions. J Clin Oncol. 2014;32(Suppl 5s):9028.

13. Thompson JF, Hersey P, Wachter E. Chemoablation of metastatic melanoma using intralesional rose bengal. Melanoma Res. 2008;18:405-11.

14. Fleming TR. One-sample multiple testing procedure for phase II clinical trials. Biometrics. 1982;38:143-51.

15. National Cancer Institute. Cancer Therapy Evaluation Program. Common terminology criteria for adverse events v.3.0 (CTCAE). December 12, 2003. http://evs.nci.nih.gov/ftp1/CTCAE/About.html.

16. Aaronson NK, Ahmedzai S, Bergman B, Bullinger M, Cull A, Duez NJ, et al. The European Organization for Research and Treatment of Cancer QLQ-C30: a quality-of-life instrument for use in international clinical trials in oncology. J Natl Cancer Inst. 1993;85:365-76.

17. Wewers ME, Lowe NK. A critical review of visual analogue scales in the measurement of clinical phenomena. Res Nurs Health. 1990;13:227-36.

18. Therasse P, Arbuck SG, Eisenhauer EA, Wanders J, Kaplan RS, Rubinstein L, et al. New guidelines to evaluate the response to treatment in solid tumors. J Natl Cancer Inst. 2000;92:205-16.
19. Illum L, Davis SS. Cellulose microspheres as a sustained release system for parenteral administration. Int J Pharma. 1982;11:323-7.

20. Kiebert GM, Jonas DL, Middleton MR. Health-related quality of life in patients with advanced metastatic melanoma: results of a randomized phase III study comparing temozolomide with dacarbazine. Cancer Invest. 2003;21:821-9.

21. Young AM, Marsden J, Goodman A, Burton A, Dunn JA. Prospective randomized comparison of dacarbazine (DTIC) versus DTIC plus interferon-alpha (IFN-alpha) in metastatic melanoma. Clin Oncol (R Coll Radiol). 2001;13:458-65.

22. Rataj D, Jankowiak B, Krajewska-Kułak E, Van Damme-Ostapowicz K, Nowecki ZI, Rutkowski P, et al. Quality-of-life evaluation in an interferon therapy after radical surgery in cutaneous melanoma patients. Cancer Nurs. 2005;28:172-8.

23. Dixon S, Walters SJ, Turner L, Hancock BW. Quality of life and cost-effectiveness of interferon-alpha in malignant melanoma: results from randomised trial. Br J Cancer. 2006;94:492-8.

24. Niraula S, Seruga B, Ocana A, Shao T, Goldstein R, Tannock IF, et al. The price we pay for progress: a meta-analysis of harms of newly approved anticancer drugs. J Clin Oncol. 2012;30:3012-9.

25. Hodi FS, O'Day SJ, McDermott DF, Weber RW, Sosman JA, Haanen JB, et al. Improved survival with ipilimumab in patients with metastatic melanoma. $N$ Engl J Med. 2010;363:711-23.

26. Robert C, Thomas L, Bondarenko I, O’Day S, Weber J, Garbe C, et al. Ipilimumab plus dacarbazine for previously untreated metastatic melanoma. $N$ Engl J Med. 2011;364:2517-26.

27. Chapman PB, Hauschild A, Robert C, Haanen JB, Ascierto P, Larkin J, et al. Improved survival with vemurafenib in melanoma with BRAF V600E mutation. N Engl J Med. 2011;364:2507-16.

28. Senzer NN, Kaufman HL, Amatruda T, Nemunaitis M, Reid T, Daniels G, et al. Phase II clinical trial of a granulocyte-macrophage colony-stimulating factor-encoding, second-generation oncolytic herpesvirus in patients with unresectable metastatic melanoma. J Clin Oncol. 2009;27:5763-71.

29. Gonzalez R, Hutchins L, Nemunaitis J, Atkins M, Schwarzenberger PO. Phase 2 trial of Allovectin-7 in advanced metastatic melanoma. Melanoma Res. 2006;16:521-6.

30. Andtbacka RHI, Collichio FA, Amatruda T, Senzer NN, Chesney J, Delman KA, et al. OPTiM: a randomized phase III trial of talimogene laherparepvec (T-VEC) versus subcutaneous (SC) granulocyte-macrophage colony-stimulating factor (GM-CSF) for the treatment (tx) of unresected stage IIIB/C and IV melanoma. $J$ Clin Oncol. 2013;31(Suppl):LBA9008.

31. Tan JK, Ho VC. Pooled analysis of the efficacy of bacille Calmette-Guérin (BCG) immunotherapy in malignant melanoma. $J$ Dermatol Surg Oncol. 1993;19:985-90.

32. Weide B, Derhovanessian E, Pflugfelder A, Eigentler TK, Radny $P$, et al. High response rate after intratumoral treatment with interleukin-2: results from a phase 2 study in 51 patients with metastasized melanoma. Cancer. 2010;116:4139-46.

33. Zitvogel L, Tesniere A, Kroemer G. Cancer despite immunosurveillance: immunoselection and immunosubversion. Nat Rev Immunol. 2006;6:715-27.

34. Polak ME, Borthwick NJ, Jager MJ, Cree IA. Melanoma vaccines: the problems of local immunosuppression. Hum Immunol. 2009;70:331-9.

35. Coventry BJ, Ashdown ML. Complete clinical responses to cancer therapy caused by multiple divergent approaches: a repeating theme lost in translation. Cancer Manag Res. 2012;4:137-49.

36. Foote MC, Burmeister BH, Thomas, Smithers BM. A novel treatment for metastatic melanoma with intralesional rose bengal and radiotherapy: a case series. Melanoma Res. 2010;20:48-51.

37. Wachter EA, Blair SO, Singer JM, Dees HC. Systemic antiCTLA-4 antibody therapy in murine models of melanoma. Cancer Res. 2013;73(8 Suppl 1):4755. 